\title{
Magnetic resonance imaging of traumatic injury to the craniovertebral junction: a case-based review
}

\author{
Anil K. Roy, MD, ${ }^{1}$ Brandon A. Miller, MD, PhD, ${ }^{1}$ Christopher M. Holland, MD, PhD, ${ }^{1}$ \\ Arthur J. Fountain Jr., MD, ${ }^{2}$ Gustavo Pradilla, MD, ${ }^{1}$ and Faiz U. Ahmad, MD1 \\ Departments of ${ }^{1}$ Neurosurgery and ${ }^{2}$ Radiology, Emory University School of Medicine, Atlanta, Georgia
}

\begin{abstract}
OBJECT The craniovertebral junction (CVJ) is unique in the spinal column regarding the degree of multiplanar mobility allowed by its bony articulations. A network of ligamentous attachments provides stability to this junction. Although ligamentous injury can be inferred on CT scans through the utilization of craniometric measurements, the disruption of these ligaments can only be visualized directly with MRI. Here, the authors review the current literature on MRI evaluation of the CVJ following trauma and present several illustrative cases to highlight the utility and limitations of craniometric measures in the context of ligamentous injury at the CVJ.
\end{abstract}

METHODS A retrospective case review was conducted to identify patients with cervical spine trauma who underwent cervical MRI and subsequently required occipitocervical or atlantoaxial fusion. Craniometric measurements were performed on the CT images in these cases. An extensive PubMed/MEDLINE literature search was conducted to identify publications regarding the use of MRI in the evaluation of patients with CVJ trauma.

RESULTS The authors identified 8 cases in which cervical MRI was performed prior to operative stabilization of the CVJ. Craniometric measures did not reliably rule out ligamentous injury, and there was significant heterogeneity in the reliability of different craniometric measurements. A review of the literature revealed several case series and descriptive studies addressing MRI in CVJ trauma. Three papers reported the inadequacy of the historical Traynelis system for identifying atlantooccipital dislocation and presented 3 alternative classification schemes with emphasis on MRI findings.

CONCLUSIONS Recognition of ligamentous instability at the CVJ is critical in directing clinical decision making regarding surgical stabilization. Craniometric measures appear unreliable, and CT alone is unable to provide direct visualization of ligamentous injury. Therefore, while the decision to obtain MR images in CVJ trauma is largely based on clinical judgment with craniometric measures used as an adjunct, a high degree of suspicion is warranted in the care of these patients as a missed ligamentous injury can have devastating consequences.

http://thejns.org/doi/abs/10.3171/2015.1.FOCUS14785

KEY WORDS craniocervical; craniovertebral; trauma; MRI

$\mathrm{T}$ HE craniovertebral junction (CVJ) is an anatomically complex region bound together by an intricate network of ligaments and articulations, all of which contribute to its overall stability. ${ }^{30}$ The bony elements of the CVJ are the occipital bone including the clivus and occipital condyles, as well as the first 2 cervical vertebrae, the atlas and axis. The major ligamentous elements of the CVJ located anterior to the spinal cord consist of accessory atlantoaxial, cruciate, alar, and apical odontoid ligaments; and the anterior atlantooccipital membrane. Pos- terior to the spinal cord, the capsular joint ligaments and the posterior atlantooccipital membrane provide stability to the CVJ. ${ }^{7,41}$ The anterior and posterior atlantooccipital membranes are continuations of the anterior and posterior longitudinal ligaments that run the length of the vertebral column. While the bony and ligamentous structures provide CVJ stability, these articulations allow great freedom of movement, permitting $25 \%$ of neck flexion-extension and up to $40^{\circ}$ of head rotation..$^{23,39}$

Although the exact proportion of cervical spine frac-

ABBREVIATIONS $\mathrm{ADI}=$ atlantodental interval; $\mathrm{AOI}=$ atlantooccipital interval; $\mathrm{BAI}=$ basion-axial interval; $\mathrm{BDI}=$ basion-dens interval; $\mathrm{CVJ}=\mathrm{craniovertebral} \mathrm{junction;} \mathrm{GCS}$

= Glasgow Coma Scale.

SUBMITTED December 2, 2014. ACCEPTED January 27, 2015.

INCLUDE WHEN CITING DOI: 10.3171/2015.1.FOCUS14785.

DISCLOSURE The authors report no conflict of interest concerning the materials or methods used in this study or the findings specified in this paper. 
tures that involve this region is not known, sources estimate that a third to half of all cervical spine injuries involve the CVJ.7-9 Many patients with CVJ trauma have an altered level of consciousness or other injuries that can make the physical examination difficult or less reliable. This can lead to delayed or missed diagnosis of CVJ injuries. Conventional radiographs or CT scans can reveal bony anatomy with great detail and have a high sensitivity for fractures. However, many bony injuries of the CVJ are not inherently biomechanically unstable and therefore do not require surgical intervention. Conversely, patients with unstable CVJ injuries requiring surgery may not necessarily have fractures. Therefore, determining the integrity of ligamentous structures of the CVJ is paramount in deciding whether surgical stabilization is necessary. ${ }^{11}$ Prior to the widespread use of MRI in the evaluation of spinal trauma, methods to determine CVJ instability were based on bony measurements. ${ }^{6,28,29,31,36,37}$ While these methods, referred to as craniometrics, are useful, MRI is playing an ever greater role in CVJ trauma, and its use continues to increase over time.

In the current paper, we review the current literature on the MRI evaluation of patients with CVJ trauma. Additionally, we present 8 illustrative cases from our institution to highlight key MRI findings indicative of unstable ligamentous injury and the need for surgical intervention.

\section{Methods}

We retrospectively reviewed a prospectively populated neurosurgical database from July 2011 to August 2014 for the adult neurosurgical service at a Level 1 trauma center to identify patients with cervical spine trauma who underwent CVJ or antlantoaxial fusion and preoperative MRI evaluation. Clinical evaluations, including initial Glasgow Coma Scale (GCS) score and neurological examinations, were performed. All neuroimages were reviewed by the senior neuroradiologist (A.F.) with emphasis on the following injury complexes: violation of the occipitocervical joint capsule, disruption of the transverse ligament of the atlas and its bony attachments, and injury to other ligaments of the CVJ. Craniometric measurements were performed on CT scans for all patients and were compared with normative values to evaluate the sensitivity of these measures for ligamentous injury. MRI was considered the gold standard for detection of ligamentous injury. Institutional review board approval was obtained for this retrospective study with a waiver of informed consent.

A detailed literature review was conducted with a PubMed/MEDLINE search using the keywords "craniovertebral trauma MRI," "craniocervical trauma MRI," "craniocervical imaging," and "craniovertebral imaging." We initially identified 858 papers through separate searches. These were analyzed for duplicates, and abstracts were reviewed. The results were analyzed to select studies discussing the appearance of CVJ ligaments on MRI. These studies range from purely descriptive studies of MRI to case series of CVJ trauma. We then narrowed these studies down to 15 papers that focused on MRI findings for CVJ trauma.

\section{Results}

Eight patients were identified from the review of our database. The demographics, salient imaging findings, and surgical interventions for these patients are presented in Table 1. The most common mechanism of injury in our patients was high-speed motor vehicle accident. Nearly half of the patients had a neurological examination clouded by intubation or traumatic brain injury. Due to the heterogeneity of cases, there was not a common criterion that triggered the clinical decision to perform MRI. Craniometric measurements are not routinely performed or documented in the radiology or neurosurgical patient records. At our institution, MRI is frequently used in our trauma population, particularly in cases of suspected ligamentous injury.

Increased T2 signal along the posterior interspinous ligaments and muscles was demonstrated in all cases and is thought to reflect strain or tear, but is not necessarily indicative of gross instability (Fig. 1). Injury to the transverse ligament of the atlas, defined as increased T2 signal at the insertion of the ligament, was present in 6 of 8 reviewed cases (Fig. 2). Note that avulsion of the transverse ligament from its sites of insertion can be visualized on $\mathrm{CT}$ as illustrated in Fig. 3. Capsular injury defined as in-

TABLE 1. Patient characteristics, injury mechanism, imaging details, and surgical intervention

\begin{tabular}{|c|c|c|c|c|c|c|c|}
\hline $\begin{array}{l}\text { Case } \\
\text { No. }\end{array}$ & $\begin{array}{l}\text { Age (yrs), } \\
\text { Sex }\end{array}$ & Mechanism & $\begin{array}{l}\text { GCS Score, Initial } \\
\text { Examination Finding }\end{array}$ & Fracture & $\begin{array}{c}\mathrm{TL} \\
\text { Injury }\end{array}$ & $\begin{array}{l}\text { Capsular } \\
\text { Injury }\end{array}$ & Surgery \\
\hline 1 & $14, F$ & MVC & $4 \mathrm{~T}$, extensor posturing & None & No & $\mathrm{AA}$ & Oc-C4 fusion \\
\hline 2 & $40, M$ & MCC & 9T, localizing & C-1 lateral mass & Yes & $\mathrm{AA}, \mathrm{AO}$ & $\begin{array}{l}\text { Oc-C3 fusion, } \mathrm{C} 5-7 \\
\text { ACDF }\end{array}$ \\
\hline 3 & $74, \mathrm{~F}$ & MVC & 9T, localizing & C1-2 subluxation, C-7 TP & Yes & None & Oc-C4 fusion \\
\hline 4 & $25, F$ & MVC & $11 \mathrm{~T}$, quadriplegic & Type 2 dens & Yes & AA & C1-2 fusion \\
\hline 5 & $60, F$ & MVC & 15 , intact & Type 2 dens & Yes & None & C1-2 fusion \\
\hline 6 & $16, F$ & MVC & 15 , intact & $\begin{array}{l}\text { C1-2 subluxation, rt C5-6 \& } \\
\text { It C-4 facet }\end{array}$ & Yes & $\mathrm{AO}$ & C1-2 fusion \\
\hline 7 & $58, M$ & Fall & 15 , intact & Type 2 dens & No & AA & C1-2 fusion \\
\hline 8 & $39, F$ & MVC & $10 \mathrm{~T}$, localizing rt & C-2 Hangman's & Yes & AA & C1-3 fusion \\
\hline
\end{tabular}

$\mathrm{AA}=$ atlantoaxial; $\mathrm{ACDF}=$ anterior cervical discectomy and fusion; $\mathrm{AO}=$ atlantooccipital; $\mathrm{MCC}=$ motorcycle collision; $\mathrm{MVC}=$ motor vehicle collision; $\mathrm{Oc}=$ occiput; $\mathrm{T}$ = intubated; $\mathrm{TL}$ = transverse ligament; $\mathrm{TP}=$ transverse process. 


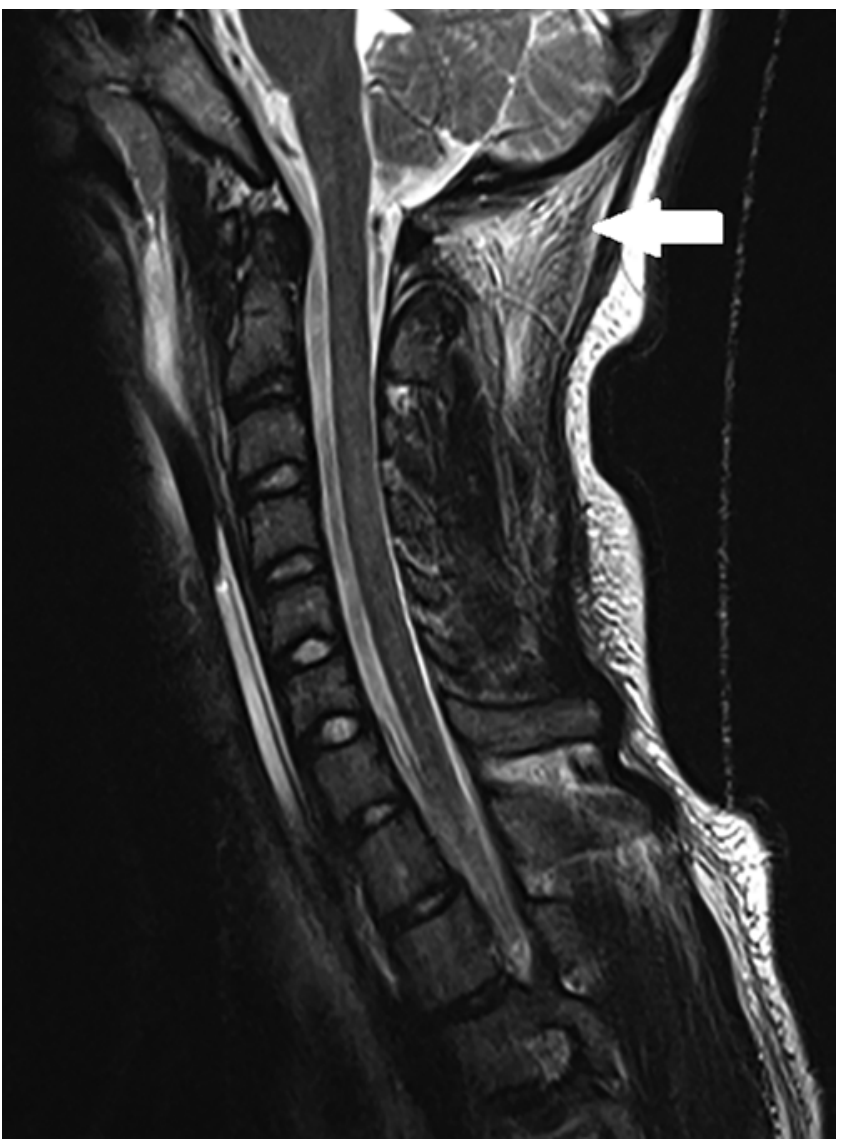

FIG. 1. Case 1. Sagittal T2-weighted image demonstrating increased signal (arrow) within the posterior musculature that is consistent with strain of these muscles, but not necessarily ligamentous injury or instability.

creased T2 signal within the occipitoatlantal or atlantoaxial joints is illustrated in Fig. 4. MRI was also able to detect epidural or subdural hematoma in the spinal canal as well as spinal cord contusions as demonstrated in Fig. 5.

One patient (Case 1) who was involved in a high-speed motor vehicle accident with ejection was brought to our trauma center intubated. At presentation, her GCS score was $4 \mathrm{~T}$ (intubated) and she was extensor posturing. A CT scan of the cervical spine was obtained, and while no fracture was identified, a subdural hematoma was revealed at

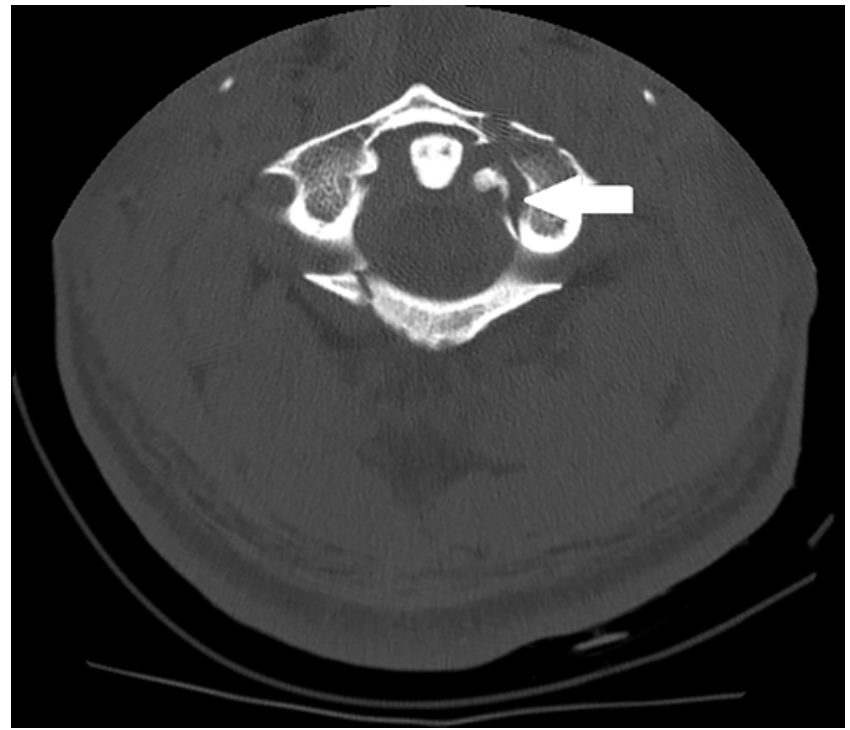

FIG. 3. Case 3. Axial CT image showing avulsion of the left transverse ligament attachment along with fracture of the left lateral mass of $\mathrm{C}-2$ (arrow).

the foramen magnum. Presence of a retroclival or subdural hematoma at the CVJ can be indicative of an occult CVJ injury. ${ }^{5,17}$ Given clinical suspicion for spinal cord injury or ligamentous instability, subsequent MRI was performed and revealed increased fluid in the $\mathrm{C} 1-2$ facet joints with intact cruciate ligaments (Fig. 6). The patient underwent instrumented occipitocervical fusion for stabilization.

A summary of the craniometric measurements derived from CT images used to evaluate CVJ stability in our patient cohort is reported in Table 2. Normative values for these measurements based on recent evidence are presented in Table $3 .{ }^{31}$ The basion-axial interval (BAI) was found to be unreliable by Rojas et al. ${ }^{31}$ and was therefore not measured in our study. We found an elevated basion-dens interval (BDI) greater than $8.5 \mathrm{~mm}$ in 2 patients (Cases 3 and 6). The same 2 patients also had Powers ratios in the intermediate range (0.9-1.0). MRI performed in these 2 patients did reveal transverse ligament injury; however, several other patients with clear ligamentous damage (Cases 2, 4, 5, and 8) had normal values for the atlantodental interval (ADI), rule of Spence, and Powers ratio. Case
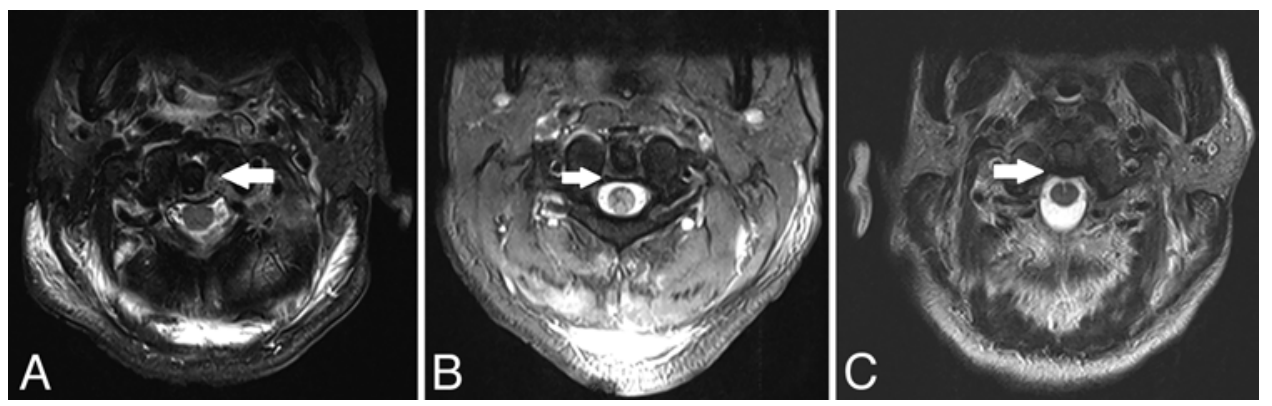

FIG. 2. A: Case 3. Axial T2-weighted image demonstrating increased signal along the left transverse ligament attachment (arrow), indicative of injury. B: Case 4. Axial T2-weighted image demonstrating discontinuity of the attachment of the right transverse ligament (arrow). Increased signal is also present ventral to the transverse ligament, indicative of disruption of its apposition with the dens. C: Case 7. Axial T2-weighted image demonstrating an intact transverse ligament, which appears as a hypointense band dorsal to the dens (arrow). Note the absence of increased signal within or at the attachment of the transverse ligament. 


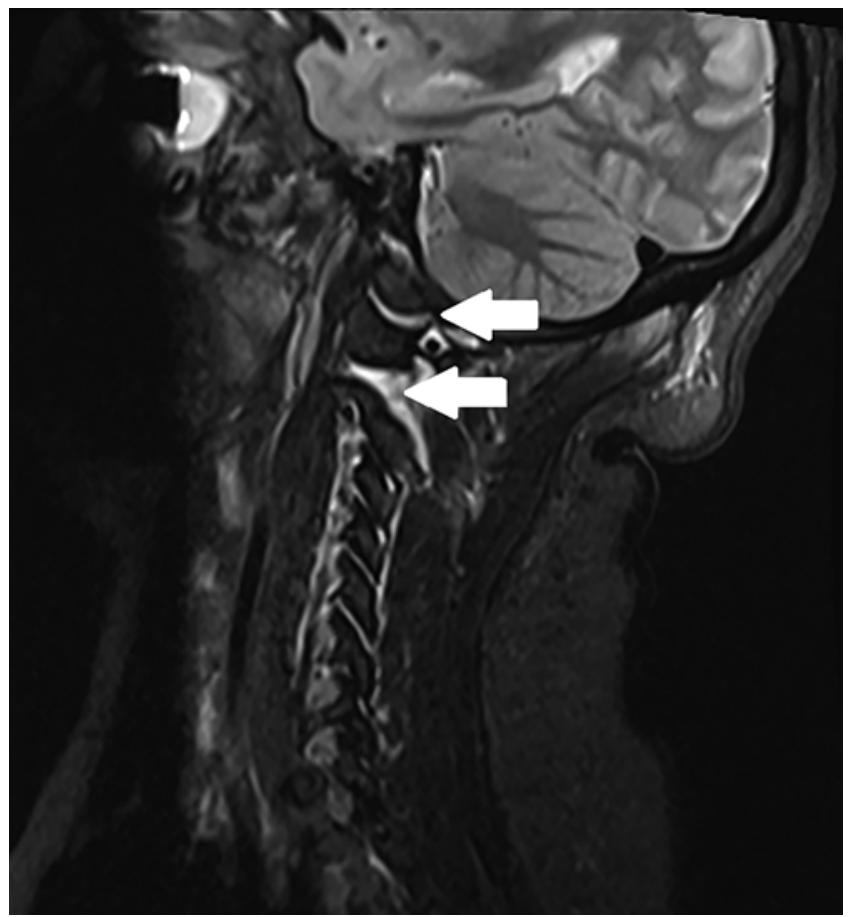

FIG. 4. Case 6. Sagittal T2-weighted image demonstrating increased signal in the atlantooccipital (upper arrow) and atlantoaxial (lower arrow) joints consistent with capsular injury.

2 had complete avulsion of the transverse ligament attachment to the lateral mass with entirely normal craniometric measurements. Recent evidence has highlighted the atlantooccipital interval (AOI) as perhaps being a more sensitive indicator of atlantooccipital dislocation, although normative values have not been clearly established. ${ }^{6,29}$ Using a cutoff of $1.4 \mathrm{~mm},{ }^{31}$ we found an elevated AOI in 4 of 8 patients (Cases 2, 3,6, and 8). All 4 of these patients had transverse ligament injury, and 2 of these patients had accompanying occipitocervical capsular injuries. Conventionally, ADI values based on plain radiographs are less than $3 \mathrm{~mm}$ for males and less than $2.5 \mathrm{~mm}$ for females. ${ }^{14}$ However, this metric was modified to a normative value of $2 \mathrm{~mm}$ for both sexes when applied to CT images. ${ }^{31} \mathrm{Ap}-$ plication of this modified measure in our cohort results in an elevated and thus abnormal ADI in 4 of 8 cases (Cases $1,2,3$, and 6).

In summary, the cases we present here demonstrate the inability of craniometric measurements to rule out ligamentous instability of the CVJ. Most craniometric measurements are intended to evaluate occipitocervical instability (ADI, AOI, BDI, and Powers ratio). Examining these measurements in the 3 patients who underwent occipitocervical fusion (Cases 1,2, and 3) revealed that although the ADI was abnormal in all 3 patients, the AOI was abnormal in only 2 patients, and the BDI and Powers ratio were only abnormal in 1 patient. Similarly, the rule of Spence, designed to predict transverse ligament integrity, was normal in all of our patients, 5 of whom had transverse ligament rupture seen on MRI. Taken together, these findings highlight the inability of craniometric measurements to exclude CVJ ligamentous injury and the utility of MRI in the detection of CVJ instability.

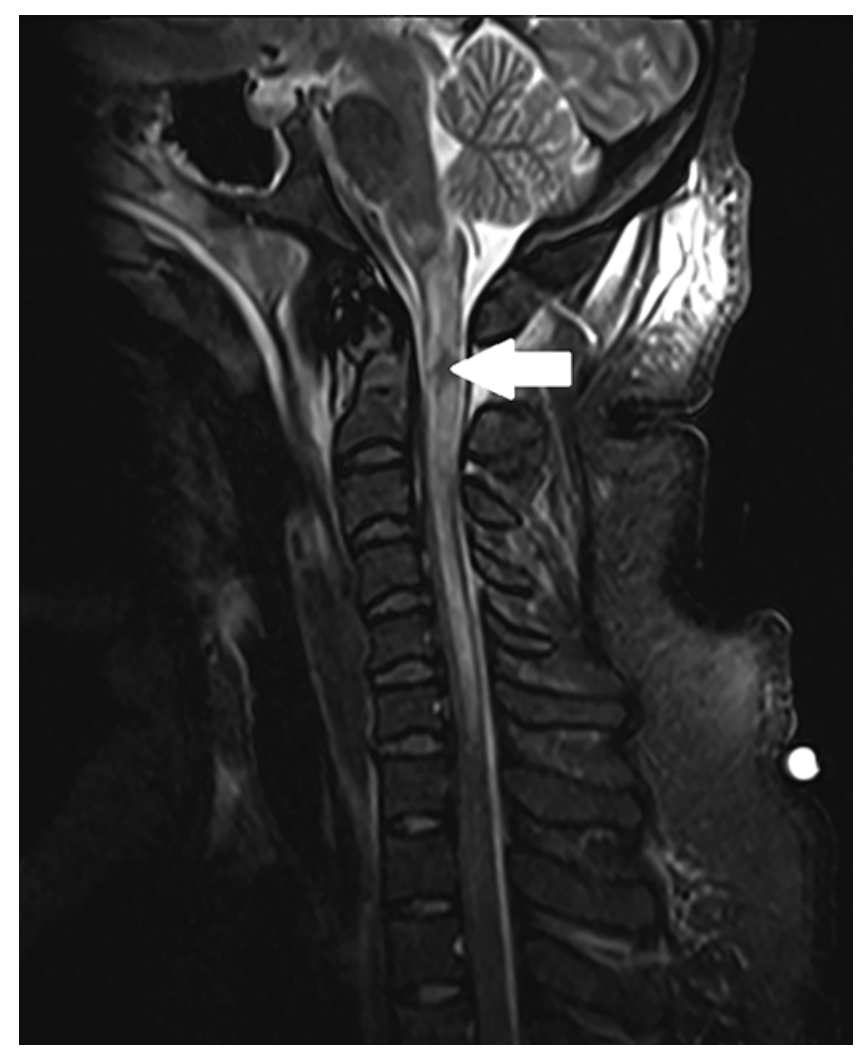

FIG. 5. Case 5. Sagittal T2-weighted image demonstrating hypointensity (arrow) at the level of the dens consistent with a spinal cord hematoma. Extensive increased T2 signal in the spinal cord both rostral and caudal to this level is present and consistent with edema.

\section{Review of MRI in CVJ Trauma}

Following the development and application of MRI, early reports provided basic descriptions of the MRI appearance of the CVJ. ${ }^{19,21}$ Lee et al. ${ }^{19}$ compared 35 patients with heterogeneous CVJ abnormalities, including traumatic dens fracture, to 10 control subjects. In this study, an intermediately weighted image between $\mathrm{T} 1$ and $\mathrm{T} 2$ was found to be superior for visualizing dens fractures. Dickman et al. ${ }^{11}$ provided one of the first reports of MRI spe-
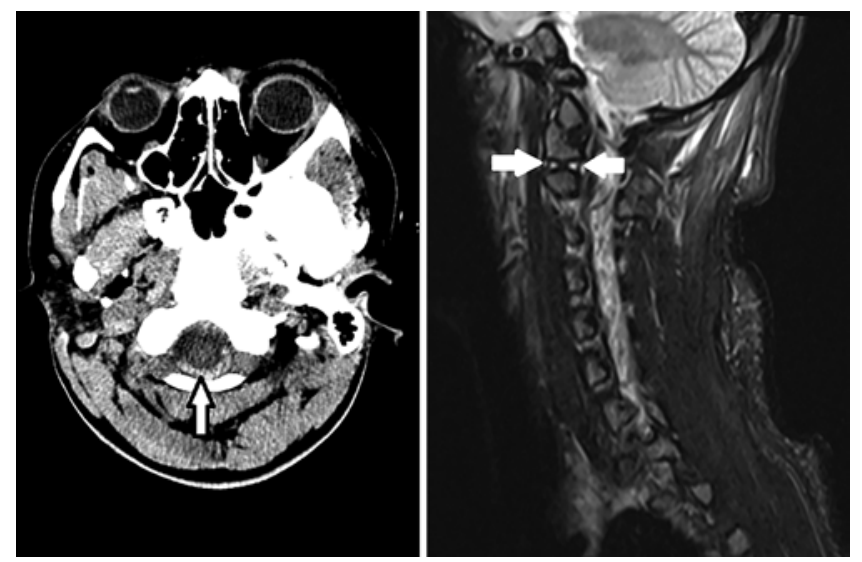

FIG. 6. Case 1. Left: Axial CT image revealing hyperdensity (arrow) within the spinal canal at the level of the foramen magnum with no fractures. Right: Sagittal T2-weighted image demonstrating increased signal (arrows) within the C1-2 joint consistent with capsular injury. 
TABLE 2. Occipitocervical radiographic parameters

\begin{tabular}{ccccc}
\hline Case No. & ADI $(\mathrm{mm})$ & AOI $(\mathrm{mm})$ & $\mathrm{BDI}(\mathrm{mm})$ & Powers Ratio \\
\hline 1 & 2.3 & 1 & 3.6 & $25.6 / 41.3=0.62$ \\
\hline 2 & 3 & 1.5 & 5.5 & $30.6 / 41.0=0.74$ \\
\hline 3 & 3.5 & 1.9 & 12.1 & $33.1 / 35.7=0.93$ \\
\hline 4 & 1 & 1.1 & 4.9 & $26.1 / 37.2=0.70$ \\
\hline 5 & 0.9 & 0.8 & 5.2 & $27.6 / 37.6=0.73$ \\
\hline 6 & 3.4 & 1.6 & 11.9 & $33.8 / 36.3=0.93$ \\
\hline 7 & 0.8 & 1 & 4.9 & $31.8 / 40.3=0.79$ \\
\hline 8 & 0.7 & 1.4 & 4.7 & $29.2 / 39.4=0.74$ \\
\hline
\end{tabular}

cifically for CVJ trauma, describing the transverse ligament as a crucial stabilizing component of the atlantoaxial region and demonstrating its appearance on MRI. In their study, the transverse was best imaged with gradient echo sequences wherein it appears as a hypointense structure. Ligament tears are visible as clear anatomical disruptions with high signal intensity on gradient echo sequences.

Pfirrmann et al. ${ }^{26}$ examined the MRI appearance of the alar ligament in healthy individuals and found it to be isointense to muscle on T1-weighted and T2-weighted images. The authors demonstrated that coronal images best showed the course of the ligament and interestingly found that $36 \%-48 \%$ of individuals without injury had detectable C1-2 effusions. However, in another study comparing healthy volunteers to patients with a history of cervical spine trauma, Willauschus et al. ${ }^{43}$ found no difference in the MRI appearance of the alar ligaments.

Several studies and a meta-analysis have been conducted regarding the MRI appearance of cervical ligaments following whiplash injuries. ${ }^{18,20}$ Krakenes and Kaale $^{18}$ reported that proton density scans best demonstrated increased signal within the alar and transverse ligaments in patients with whiplash injury compared with control subjects. However, in a meta-analysis of 6 studies by $\mathrm{Li}$ et al. ${ }^{20}$ no differences were seen in the MRI appearance between controls and patients with whiplash injury.

Our review found only 4 case series that specifically addressed craniocervical dislocation with attention to the MRI findings. ${ }^{2,10,15,28}$ Interestingly, with the exception of the study by Dickman et al.. ${ }^{10}$ all studies demonstrated the inadequacy of the Traynelis system for atlantooccipital dislocation classification, ${ }^{40}$ noting that all 3 Traynelis subtypes (anterior, posterior, and vertical) may be present in atlantooccipital dislocation. These studies also presented novel alternative classification schemes for craniocervical dislocation and are summarized in Table 4.

As with craniometric measurements, many groups have proposed rating scales or classification schemes for CVJ injuries based on MRI findings. Dickman et al. ${ }^{11}$ retrospectively reviewed 39 adult patients with cervical spine trauma and injury to the transverse ligament seen on MRI, classifying these cases into 2 subtypes. Type I involved disruptions of the substance of the transverse ligament, while Type II involved fractures or avulsions involving the tubercle that accommodates the insertion of the transverse ligament. Horn and colleagues ${ }^{15}$ also recommended 2 grades: Grade I with normal CT and elevated T2 signal on
TABLE 3. Normative CVJ radiographic parameters on CT

\begin{tabular}{ll}
\hline \multicolumn{1}{c}{ Interval } & Normal Distance $(\mathrm{mm})$ \\
\hline $\mathrm{ADI}(\mathrm{mm})$ & $<2$ (male \& female) \\
\hline $\mathrm{AOI}(\mathrm{mm})$ & $\leq 1.4$ \\
\hline $\mathrm{BAl}(\mathrm{mm})$ & Not reliable \\
\hline $\mathrm{BDI}(\mathrm{mm})$ & $<8.5$ \\
\hline Powers ratio & $<0.9$ \\
\hline Rule of Spence $(\mathrm{mm})$ & $<7$ \\
\hline
\end{tabular}

MRI of posterior ligaments or occipitocervical joints and Grade II with an abnormal CT or grossly abnormal MRI findings in the occipitocervical joints, tectorial membrane, or alar or cruciate ligament. External orthosis is recommended for the former and surgical stabilization for the latter.

Bellabarba et al..$^{2}$ reviewed records of 17 patients with CVJ injury who subsequently underwent occipitocervical fusion. Four of the 17 patients were diagnosed primarily based on MRI findings, although the precise imaging characteristics demonstrating ligamentous injury were not reported. In their review, the authors proposed a 3-tiered classification for CVJ injuries. The difference between Stages 1 and 2, which both include MRI evidence of injury to osseoligamentous stabilizers, is a distraction of greater than $2 \mathrm{~mm}$ with provocative traction radiography in Stage 2. Stage 3 is classified as craniocervical malalignment (BDI or BAI) of greater than $2 \mathrm{~mm}$ on static radiography. This classification schema is not clinically applicable in the present day, as current practice at most institutions would be for MR images to be obtained in any patient with CVJ instability prior to applying traction. Moreover, craniometric measurements were found to be unreliable in our patients. Finally, Radcliff et al. ${ }^{28}$ reviewed a series of 18 patients with CVJ injuries and focused not only on the CVJ ligaments but also the occipitocervical and atlantoaxial joints. The authors primarily relied on increased T2 or STIR changes to identify injury to the ligaments or articular joints. In their study, a 2-tiered classification system is proposed with Type I having only atlantoaxial joint injury and Type II with occipitocervical and atlantoaxial joint injuries. Cruciate ligament injury without any associated joint subluxation was also characterized as Type I.

\section{Discussion}

Current neurosurgical guidelines for the management of cervical spine trauma recommend CT imaging in awake symptomatic patients and in obtunded patients in whom there is a suspicion of cervical spine trauma..$^{38,42}$ While the use of CT imaging meets the criteria for Level 1 recommendations, these evidence-based guidelines are only able to make Level 3 recommendations regarding the use of MRI for evaluating the cervical spine and occipital condyles in trauma patients. In the absence of well-established guidelines, the decision to use MRI in the setting of acute cervical spine trauma is often left to the treating trauma, neurosurgery, or orthopedic surgery clinician.

Much work has been done to establish craniometric assessment as a proxy for ligamentous integrity., ${ }^{3,6,29,31}$ In our 
TABLE 4. Review of CVJ grading scales and associated treatment recommendations

\begin{tabular}{|c|c|c|}
\hline Authors \& Year & Grading Scale & Treatment \\
\hline \multirow[t]{2}{*}{ Dickman et al., 1996} & I: Disruption of substance of TL & C1-2 fusion \\
\hline & II: Fracture or avulsion involving the tubercle for insertion of TL & External orthosis \\
\hline \multirow[t]{3}{*}{ Bellabarba et al., 2006} & $\begin{array}{l}\text { 1: MRI evidence of injury to craniocervical osseoligamentous stabilizers; craniocervical alignment w/in } 2 \\
\mathrm{~mm} \text { of normal; distraction of } \leq 2 \mathrm{~mm} \text { on provocative traction radiography }\end{array}$ & \\
\hline & $\begin{array}{l}\text { 2: MRI evidence of injury to craniocervical osseoligamentous stabilizers; craniocervical alignment w/in } 2 \\
\text { mm of normal; distraction of }>2 \mathrm{~mm} \text { on provocative traction radiography }\end{array}$ & \\
\hline & 3: Craniocervical malalignment of $>2 \mathrm{~mm}$ on static radiography & \\
\hline \multirow[t]{2}{*}{ Horn et al., 2007} & $\begin{array}{l}\text { I: Normal findings on CT based on established methods of diagnosis (Powers ratio, BDI, BAI-BDI, X-line) } \\
\text { w/ moderately abnormal findings on MRI (high signal in posterior ligaments or OA joints) }\end{array}$ & External orthosis \\
\hline & $\begin{array}{l}\text { II: } \geq 1 \text { abnormal finding on CT based on established diagnostic criteria or grossly abnormal MRI findings in } \\
\text { OA joints, tectorial membrane, alar ligaments or cruciate ligaments }\end{array}$ & Spinal fixation \\
\hline \multirow[t]{2}{*}{ Radcliff et al., 2012} & I: Atlantoaxial; intact OA capsule; disrupted craniocervical ligaments; displacement of BDI, C1-2 joints & C1-2 fusion \\
\hline & $\begin{array}{l}\text { II: Occipitoatlantoaxial; disrupted OA capsule; disrupted craniocervical ligaments; displacement of BDI, OA } \\
\text { joints, C1-2 joints }\end{array}$ & Oc-C2 fusion \\
\hline
\end{tabular}

$\mathrm{OA}=$ occipitoatlantal.

series, solely relying on CT for assessment of CVJ stability would have underestimated the extent of injury in several of our patients. In Case 1, the absence of CVJ bony injury with associated capsular injury highlights the need for heightened clinical suspicion in these patients. Furthermore, MRI is more sensitive than the rule of Spence for detecting transverse ligament injury ${ }^{10}$ as demonstrated in our series. Other investigators have shown that certain C-1 fracture patterns, even with an intact transverse ligament, may be unstable. ${ }^{4}$ Taken together, this work illustrates the hazard of relying solely on craniometric measurements to determine the stability of the CVJ.

Studies have demonstrated the greater sensitivity of MRI for detecting cervical spine injuries than $\mathrm{CT}$ or plain radiographs alone and that the addition of MRI to CT imaging can alter patient management. ${ }^{22,38}$ Although there is no official consensus in recently published guidelines, many authors consider MRI to be the gold standard for detecting cervical spine injuries. ${ }^{13,24}$ Studies have shown flexion/extension radiographs to be suboptimal in the evaluation of obtunded trauma patients, ${ }^{1,16}$ and current guidelines emphasize the use of MRI rather than dynamic radiographs in these patients. ${ }^{32-35}$ It is our current practice to use MRI rather than flexion/extension radiographs in all patients in whom ligamentous injury is suspected.

Current cervical spine guidelines do not provide recommendations as to the use of MRI in CVJ injuries. ${ }^{32-34}$ However, there is a Level 3 recommendation for the consideration of surgical fusion in isolated C-1 fractures with transverse ligament disruption, although the use of MRI to evaluate the transverse ligament is not specifically recommended. ${ }^{32}$ As discussed previously, MRI findings in CVJ trauma can be quite varied, ranging from alar, transverse ligament, and posterior ligamentous injuries to capsular injury, spinal canal hematoma, and spinal cord contusions. It is important to note that the increased sensitivity of MRI may result in surgeons interpreting any abnormal signal as pathological, as reported by Pfirrmann et al., ${ }^{26}$ and therefore caution is advised. These findings have to be interpreted in the appropriate clinical context. At our in- stitution, attention is directed primarily to alar, transverse ligament, and capsular injuries as important radiographic features in the decision-making process. Given its ubiquitous nature, we do not routinely include increased T2 signal in the posterior interspinous ligaments and muscles as a factor in clinical decision making.

Established classification systems for CVJ injuries are based on bony injuries and measures; however, CVJ stability is largely dependent on ligamentous integrity., ${ }^{7,23}$ Softtissue injury at the CVJ can occur in the presence of subtle physical examination findings and can have tragic consequences if missed. ${ }^{27}$ The cases presented here emphasize not only the often subtle radiographic findings associated with CVJ ligamentous injuries, but also the discordance of classic fracture-based classification schemes and MRI findings in CVJ trauma. As MRI becomes increasingly available for the early assessment of trauma patients, standardized algorithms for its use and interpretation will need to be developed.

It should be emphasized that we do not recommend routine MRI for all patients with suspected cervical spine injuries. Evidence strongly points to the limited value of the broad application of MRI in such a setting. ${ }^{12,25}$ However, the CVJ is unique in the critical role played by ligamentous attachments. We recommend MRI of the cervical spine for patients with a high-energy mechanism of injury and an unreliable neurological examination with or without evidence of CVJ abnormality on CT. While the clinical utility and cost effectiveness of this strategy need to be evaluated in prospective studies, we believe the high cost of a missed CVJ injury warrants a low threshold for the use of MRI in this setting.

\section{Conclusions}

Ligamentous injury is often the indication for surgical stabilization of the CVJ. Changes associated with CVJ ligamentous injuries may be subtle on CT imaging, and there should be a low threshold for the use of MRI in cases of suspected cervical spine injury in patients with 
high-energy mechanisms of injury. Neurosurgeons must be able to recognize the CT and MRI characteristics of CVJ instability to determine when surgical treatment is warranted. Most recommendations for the management of patients with verified or suspected cervical spine or CVJ injuries comes from Class 3 evidence, and the use of MRI in evaluation of these patients is largely based on clinical judgment. The increasing availability of MRI will likely lead to a lower threshold for its use, and guidelines should be established to help limit missed injuries as well as the expense of unnecessary imaging.

\section{References}

1. Anglen J, Metzler M, Bunn P, Griffiths H: Flexion and extension views are not cost-effective in a cervical spine clearance protocol for obtunded trauma patients. J Trauma 52:54-59, 2002

2. Bellabarba C, Mirza SK, West GA, Mann FA, Dailey AT, Newell DW, et al: Diagnosis and treatment of craniocervical dislocation in a series of 17 consecutive survivors during an 8-year period. J Neurosurg Spine 4:429-440, 2006

3. Bertozzi JC, Rojas CA, Martinez CR: Evaluation of the pediatric craniocervical junction on MDCT. AJR Am J Roentgenol 192:26-31, 2009

4. Bransford R, Falicov A, Nguyen Q, Chapman J: Unilateral C-1 lateral mass sagittal split fracture: an unstable Jefferson fracture variant. J Neurosurg Spine 10:466-473, 2009

5. Casey D, Chaudhary BR, Leach PA, Herwadkar A, Karabatsou K: Traumatic clival subdural hematoma in an adult. J Neurosurg 110:1238-1241, 2009

6. Chang W, Alexander MT, Mirvis SE: Diagnostic determinants of craniocervical distraction injury in adults. AJR Am J Roentgenol 192:52-58, 2009

7. Debernardi A, D’Aliberti G, Talamonti G, Villa F, Piparo M, Collice M: The craniovertebral junction area and the role of the ligaments and membranes. Neurosurgery 68:291-301, 2011

8. Debernardi A, D’Aliberti G, Talamonti G, Villa F, Piparo M, Ligarotti G, et al: Traumatic injuries to the craniovertebral junction: a review of rare events. Neurosurg Rev 37:203216, 2014

9. Deliganis AV, Baxter AB, Hanson JA, Fisher DJ, Cohen WA, Wilson AJ, et al: Radiologic spectrum of craniocervical distraction injuries. Radiographics 20:S237-S250, 2000

10. Dickman CA, Greene KA, Sonntag VK: Injuries involving the transverse atlantal ligament: classification and treatment guidelines based upon experience with 39 injuries. Neurosurgery 38:44-50, 1996

11. Dickman CA, Mamourian A, Sonntag VK, Drayer BP: Magnetic resonance imaging of the transverse atlantal ligament for the evaluation of atlantoaxial instability. J Neurosurg 75:221-227, 1991

12. Dreizin D, Letzing M, Sliker CW, Chokshi FH, Bodanapally U, Mirvis SE, et al: Multidetector CT of blunt cervical spine trauma in adults. Radiographics 34:1842-1865, 2014

13. Duane TM, Cross J, Scarcella N, Wolfe LG, Mayglothling J, Aboutanos MB, et al: Flexion-extension cervical spine plain films compared with MRI in the diagnosis of ligamentous injury. Am Surg 76:595-598, 2010

14. Hinck VC, Hopkins CE: Measurement of the atlanto-dental interval in the adult. Am J Roentgenol Radium Ther Nucl Med 84:945-951, 1960

15. Horn EM, Feiz-Erfan I, Lekovic GP, Dickman CA, Sonntag VK, Theodore N: Survivors of occipitoatlantal dislocation injuries: imaging and clinical correlates. J Neurosurg Spine 6:113-120, 2007

16. Insko EK, Gracias VH, Gupta R, Goettler CE, Gaieski DF,
Dalinka MK: Utility of flexion and extension radiographs of the cervical spine in the acute evaluation of blunt trauma. $\mathbf{J}$ Trauma 53:426-429, 2002

17. Koshy J, Scheurkogel MM, Clough L, Huisman TA, Poretti A, Bosemani T: Neuroimaging findings of retroclival hemorrhage in children: a diagnostic conundrum. Childs Nerv Syst 30:835-839, 2014

18. Krakenes J, Kaale BR: Magnetic resonance imaging assessment of craniovertebral ligaments and membranes after whiplash trauma. Spine (Phila Pa 1976) 31:2820-2826, 2006

19. Lee BC, Deck MD, Kneeland JB, Cahill PT: MR imaging of the craniocervical junction. AJNR Am J Neuroradiol 6: 209-213, 1985

20. Li Q, Shen H, Li M: Magnetic resonance imaging signal changes of alar and transverse ligaments not correlated with whiplash-associated disorders: a meta-analysis of case-control studies. Eur Spine J 22:14-20, 2013

21. Lufkin R, Vinuela F, Bentson JR, Dion JE: Magnetic resonance imaging of the craniocervical junction. Comput Med Imaging Graph 12:281-292, 1988

22. Menaker J, Stein DM, Philp AS, Scalea TM: 40-slice multidetector CT: is MRI still necessary for cervical spine clearance after blunt trauma? Am Surg 76:157-163, 2010

23. Menezes AH, Traynelis VC: Anatomy and biomechanics of normal craniovertebral junction (a) and biomechanics of stabilization (b). Childs Nerv Syst 24:1091-1100, 2008

24. Muchow RD, Resnick DK, Abdel MP, Munoz A, Anderson PA: Magnetic resonance imaging (MRI) in the clearance of the cervical spine in blunt trauma: a meta-analysis. J Trauma 64:179-189, 2008

25. Panczykowski DM, Tomycz ND, Okonkwo DO: Comparative effectiveness of using computed tomography alone to exclude cervical spine injuries in obtunded or intubated patients: meta-analysis of 14,327 patients with blunt trauma. J Neurosurg 115:541-549, 2011

26. Pfirrmann CW, Binkert CA, Zanetti M, Boos N, Hodler J: MR morphology of alar ligaments and occipitoatlantoaxial joints: study in 50 asymptomatic subjects. Radiology 218:133-137, 2001

27. Przybylski GJ, Clyde BL, Fitz CR: Craniocervical junction subarachnoid hemorrhage associated with atlanto-occipital dislocation. Spine (Phila Pa 1976) 21:1761-1768, 1996

28. Radcliff K, Kepler C, Reitman C, Harrop J, Vaccaro A: CT and MRI-based diagnosis of craniocervical dislocations: the role of the occipitoatlantal ligament. Clin Orthop Relat Res 470:1602-1613, 2012

29. Radcliff KE, Ben-Galim P, Dreiangel N, Martin SB, Reitman CA, Lin JN, et al: Comprehensive computed tomography assessment of the upper cervical anatomy: what is normal? Spine J 10:219-229, 2010

30. Raybaud C: Anatomy and development of the craniovertebral junction. Neurol Sci 32 (Suppl 3):S267-S270, 2011

31. Rojas CA, Bertozzi JC, Martinez CR, Whitlow J: Reassessment of the craniocervical junction: normal values on CT. AJNR Am J Neuroradiol 28:1819-1823, 2007

32. Ryken TC, Aarabi B, Dhall SS, Gelb DE, Hurlbert RJ, Rozzelle CJ, et al: Management of isolated fractures of the atlas in adults. Neurosurgery 72 (Suppl 2):127-131, 2013

33. Ryken TC, Hadley MN, Aarabi B, Dhall SS, Gelb DE, Hurlbert RJ, et al: Management of acute combination fractures of the atlas and axis in adults. Neurosurgery 72 (Suppl 2):151-158, 2013

34. Ryken TC, Hadley MN, Aarabi B, Dhall SS, Gelb DE, Hurlbert RJ, et al: Management of isolated fractures of the axis in adults. Neurosurgery 72 (Suppl 2):132-150, 2013

35. Ryken TC, Hadley MN, Walters BC, Aarabi B, Dhall SS, Gelb DE, et al: Radiographic assessment. Neurosurgery 72 (Suppl 2):54-72, 2013 
36. Smoker WR: Craniovertebral junction: normal anatomy, craniometry, and congenital anomalies. Radiographics 14:255-277, 1994

37. Smoker WR, Khanna G: Imaging the craniocervical junction. Childs Nerv Syst 24:1123-1145, 2008

38. Stassen NA, Williams VA, Gestring ML, Cheng JD, Bankey PE: Magnetic resonance imaging in combination with helical computed tomography provides a safe and efficient method of cervical spine clearance in the obtunded trauma patient. J Trauma 60:171-177, 2006

39. Steinmetz MP, Mroz TE, Benzel EC: Craniovertebral junction: biomechanical considerations. Neurosurgery 66 (3 Suppl):7-12, 2010

40. Traynelis VC, Marano GD, Dunker RO, Kaufman HH: Traumatic atlanto-occipital dislocation. Case report. J Neurosurg 65:863-870, 1986

41. Tubbs RS, Hallock JD, Radcliff V, Naftel RP, Mortazavi M, Shoja MM, et al: Ligaments of the craniocervical junction. $\mathbf{J}$ Neurosurg Spine 14:697-709, 2011

42. Walters BC, Hadley MN, Hurlbert RJ, Aarabi B, Dhall SS,
Gelb DE, et al: Guidelines for the management of acute cervical spine and spinal cord injuries: 2013 update. Neurosurgery 60 Suppl 1:82-91, 2013

43. Willauschus WG, Kladny B, Beyer WF, Glückert K, Arnold $\mathrm{H}$, Scheithauer R: Lesions of the alar ligaments. In vivo and in vitro studies with magnetic resonance imaging. Spine (Phila Pa 1976) 20:2493-2498, 1995

\section{Author Contributions}

Conception and design: Roy, Miller. Acquisition of data: Roy. Analysis and interpretation of data: Roy. Drafting the article: Ahmad, Roy, Miller. Critically revising the article: Ahmad, Roy, Holland, Fountain, Pradilla. Reviewed submitted version of manuscript: Ahmad, Roy, Holland, Fountain, Pradilla.

\section{Correspondence}

Faiz U. Ahmad, Department of Neurosurgery, Emory University School of Medicine, 49 Jesse Hill Jr. Dr., Rm. 341, Atlanta, GA 30303. email: faiz.ahmad@emory.edu. 